\title{
Atuação e competência do Conselho Municipal de Saúde Santo Antônio do Descoberto, DF
}

\author{
Performance and competence of the Santo Antônio do Descoberto Municipal Health \\ Council, FD
}

Actuación y competencia del Consejo Municipal de Salud Santo Antônio do Descoberto, DF

Rosimary Bernardes Silva ${ }^{1}$

RESUMO: A Constituição Brasileira de 1988 e a Lei 8142/90 garantem a participação social na gestão do Sistema Único de Saúde, influenciado pelos movimentos populares que buscavam estabelecer proteção à saúde coletiva e individual, de forma democrática e organizada. A determinação das competências Básicas dos Conselhos de Saúde descrita no Decreto 333/2003, está fundamentada em princípios democráticos, que busca atender as necessidades da população e normatiza as ações dos conselhos de saúde por meio do estabelecimento de suas atribuições e diretrizes regulamentadoras.

Palavras-chave: Conselho Municipal de Saúde. Conselho de Saúde. Participação Social.

\begin{abstract}
The Brazilian Constitution of 1988 and Law 8142/90 assure social participation in the administration of the Unified Health System, which was influenced by popular movements that sought to establish collective and individual health rights in a democratic and systematic way. The determination of the core competences of Health Councils described in the Decree 333/2003 is anchored in the democratic principles, meeting the needs of the population and standardizing the actions of health councils by establishing their attributions and regulations.
\end{abstract}

Keywords: Municipal Health Council. Health Council. Social Participation.

RESUMEN: La Constitución Brasileña de 1988 y la Ley 8142/90 garantizan la participación social en la gerencia del Sistema Único de Salud. El proceso fue influenciado por los movimientos populares que buscaban establecer protección a la salud colectiva e individual, de forma democrática y sistemática. La determinación de las competencias esenciales de los Consejos de Salud descritas en el Decreto 333/2003 están fundamentad as en los principios democráticos, sanando las necesidades de la población y normalizando las acciones de los consejos de salud por establecer sus atribuciones y directrices.

Palabras Ilave: Consejo Municipal de Salud. Consejo de Salud. Participación Social.

\footnotetext{
${ }^{1}$ Bacharel em nutrição e nutricionista coordenadora do Núcleo de Apoio a Saúde da Família da Secretária Municipal de Saúde de Santo Antônio do Descoberto, DF. Email: rosimary.silva@gmail.com
} 


\section{Introdução}

A preocupação com a consolidação de normas que garantissem as políticas públicas de saúde, principalmente após a segunda grande guerra, segundo uma visão que buscavam construir plano sistematizado com dimensões preocupado em garantir a todos os brasileiros um sistema de saúde com bases universais e igualitárias a todos, tendo como ponto de partida uma concepção que promovesse a "proteção da dignidade humana e dos direitos humanos" (1).

A participação social no Sistema Único de Saúde garantida como diretriz na Constituição Brasileira de 1988 e posteriormente descrita na Lei 8142/90 criou os conselhos de saúde, que passarão ser item obrigatório na gestão do serviço de saúde, com suas competências e organização bem definidas. Aos conselhos de saúde cabe a intervenção social organizada positivada no sistema de saúde com o propósito de realizar de maneira responsável o controle social das ações e serviços de saúde. O avanço no processo de gestão com o surgimento dessa nova forma de intervenção sem duvida foi de suma importância para garantir que o cidadão intervenha no sistema de saúde fazendo uso pleno "das funções sociais da cidadania e garantindo o bem-estar dos habitantes" dessa forma os representantes tem dentro dos conselhos de saúde a importante missão de discutir os temas de saúde com foco no fortalecimento e na qualificação do controle social no Sistema Único de Saúde (2).

Essa pesquisa foi realizada com o objetivo de verificar se as ações desempenhadas pelos membros do Conselho Municipal de Saúde de Santo Antônio do Descoberto (CMSSAD) estão de acordo suas atribuições e competências estabelecidas segundo as diretrizes e estruturação de funcionamento regulamentado segundo o Estatuto do Conselho Municipal de Saúde

Após a segunda metade do século XIX aumentou a preocupação com a normatização do direito a saúde. Ideologicamente os organismos internacionais ligados aos direitos humanos se preocuparam em positivar o direito a saúde. A criação da Organização Mundial da Saúde (OMS) em 1948 desencadeou no surgimento de normas internacionais de proteção a saúde coletiva e individual, que influenciaram na consolidação no fortalecimento do serviço e ações em saúde do Direito Sanitário no Brasil (1).

A defasagem do poder aquisitivo da classe trabalhadora e o aumento da migração do campo para a cidade ocorrida na primeira metade da década de 70 , resultante de uma 
economia subordinada ao mercado externo gerou um importante desgaste político decorrente da insatisfação gerada pela concentração de riqueza. Nesse contexto, os movimentos populares alavancaram uma séria de denúncia principalmente em fóruns organizados que discutiam sobre a situação da saúde e a preocupação sobre o rumo que o país havia tomado em relação aos serviços de atenção médica, esses fóruns tornaram-se o principal ponto de partida para a Reforma Sanitária (3).

[...] Considerar como um marco deste período a realização da VIII Conferência Nacional de Saúde (VIII CNS) no ano de 1986, na qual a participação ativa de diversos segmentos da sociedade abriu a possibilidade para um modelo de política de saúde mais democrático [...] (4)

De fato, com o fim de o governo militar e a construção de novo ordenamento político, administrativo no país a participação social agora legitimada na representa um ganho significativo na expansão e fortalecimento do serviço público de saúde (4)

O aprimoramento da democracia no Brasil apresentou uma nova organização social a partir da Constituição Federal de 1988, de forma ampla a termologia cidadania foi remodelada, gerando uma importante interação entre governo e sociedade. Dessa forma, a participação social assegurada na nossa "Carta Magna" se materializa e redefine as políticas públicas. O Sistema Único de Saúde de forma inovadora estabelece a legitimidade, a participação social como diretriz operacional puncionando o controle social no serviço de saúde, contudo segundo, Vasconcelos (5) "ferramentas de informação e comunicação em saúde é inquestionável para a participação social preconizada pelo SUS"

Para Guizardi (6) "os usuários estão representados na arena das decisões políticas no campo da saúde", porém Wendhausen (7) afirma que "as decisões importantes são tomadas pelas secretarias de saúde ou seu secretário; são levadas aos conselhos as decisões menores".

É importante compreender a importância da garantia constitucional do direito a saúde, "não entendemos o direito estritamente como garantia constitucional, formalização jurídica em si mesma definida, mas como práticas de sociabilidade, princípios reguladores" $O$ fortalecimento do Movimento Sanitário subsidiou as fontes doutrinarias inspirando a construção do SUS e garantindo o direito constitucional à saúde (6) que ficou consignado na Constituição de 1988: 
Art. 198 As ações e serviços públicos de saúde integram uma rede regionalizada e hierarquizada e constituem um sistema único, organizado de acordo com as seguintes diretrizes:

I - Descentralização, com direção única em cada esfera de governo;

II - Atendimento integral, com prioridade para as atividades preventivas, sem prejuízo dos serviços assistenciais;

III - participação da comunidade. (8).

O Conselho Nacional de Saúde (CNS) estabelece a composição representativa dos Conselhos de Saúde, respeitando paridade entre usuários e representantes dos demais segmentos estabelecidos na Lei 8.142/90. Dessa forma os Conselhos de Saúde são entendidos como órgãos colegiados de caráter debilerativo, cuja atuação envolve a formulação, preposição de estratégia e controle das execuções das políticas públicas e saúde que integram o Sistema Único de Saúde (SUS) nas esferas de governos municipais, estaduais e federal, podendo ainda ser organizado os Conselhos Regionais, Distritais, Locais e Distritais Indígenas, estes devem ser coordenados pelos Conselhos de Saúde do seu ente federativo correspondente (9).

Art. 1ํ- - O Sistema Único de Saúde - SUS de que trata a Lei ํㅜ 8.080, de 19 de setembro de 1990, contará, em cada esfera de governo, sem prejuízo das funções do Poder Legislativo, com as seguintes instâncias colegiadas:

I - a Conferência de Saúde, e

II - o Conselho de Saúde.

$\S 1^{\circ}$ - A Conferência de Saúde reunir-se-á cada 4 anos com a representação dos vários segmentos sociais, para avaliar a situação de saúde e propor as diretrizes para a formulação da política de saúde nos níveis correspondentes, convocada pelo Poder Executivo ou, extraordinariamente, por este ou pelo Conselho de Saúde.(10)

O Conselho Nacional de Saúde (CNS) publicou em novembro de 2003 a Resolução nํ 333 que aprovou as diretrizes para criação, reformulação, estruturação e funcionamento dos Conselhos de Saúde, após amplas discussões na 9ª̣, 10 e 11a Conferência de Saúde com bases legais na Constituição Federal de 1988, Lei 8080/90 e a Lei 8142/90, com o objetivo de fortalecer os Conselhos de Saúde.

Segundo a Resolução a criação e reformulação dos Conselhos de Saúde devem ocorrer seguindo os princípios democráticos, de forma a atender as necessidades da população estabelecidas nas conferências de saúde de cada ente federativo, viabilizando a 
discutição, acompanhamento, avaliação e fiscalização inclusive os aspectos econômicos e financeiros dos Planos de Saúde (10).

As competências Básicas dos Conselhos de Saúde estão descritas na lei n: 8142/1990, para melhor compreender podemos distribuí-los em dois grupos distintos: no primeiro estão às competências ligadas ao controle e planejamento das e segundo seria a área de articulação (10).

A democracia constitui um valor fundamental, sendo o Brasil um Estado Democrático de Direito onde a saúde é tida como um direito social de valor universal e de relevância pública ligada à proteção e a dignidade humana é indispensável à participação social visando o aprimoramento na elaboração, planejamento e efetivação das políticas públicas conforme as normativas legais do ordenamento jurídico do Direito a Saúde (11).

A abertura de espaços para discussão, podemos destacar aqui a $8^{\circ}$ Conferência de Saúde foi um grande avanço para legitimar a participação social na consolidação do Sistema de Saúde estabelecido na Constituição de 1988, outros projetos que se destacaram na consolidação do atual sistema de saúde brasileiro foram o Plano de Localização de Unidade de Serviço, que em termos práticos possibilitaram a ação programada de saúde coletiva e o projeto Monte Claros, destacado principalmente pela implantação de uma administração democrática descentralizada e integral da assistência de saúde.

Portanto, ressaltamos que um dos aspectos mais relevantes desses movimentos sociais foi, e tem sido, na medida em que essas referências encontram-se resentes, inclusive nos discursos que coletamos junto aos representantes do Conselho Municipal de Saúde, o de "cristalizar" o significado de cidadania, não somente em termos de conquistas materiais e sociais, mas também na constituição de uma "identidade" que se opõe à ideia da exclusão, ou de uma sociedade com dois tipos de "cidadãos". O termo cidadania deixa de ter seu significado meramente "jurídico", para indicar esse "emblema" do "Movimento Social (12).

Dallari (12) apresenta uma reflexão a respeito do uso da terminologia participação social, segundo a autora "o termo participação tem sido amplamente utilizado para se a movimento". Dessa forma temos uma substituição ideológica do termo movimento social por participação social, que de forma especifica, quando analisamos a transição democrática dos anos 80 , amplia nossa identidade social, firmado os direitos de cidadania nos planos político e econômico no plano institucional da sociedade. 


\section{Metodologia}

O trabalho foi realizado a partir de um estudo exploratório documental analíticosintético. Segundo Alvarenga (13) "pesquisa desse formato visa à inclusão de textos normativos para a avaliação e aplicação de fatos sociais concretos devendo considerar os limites elementares da investigação”. E foram utilizadas fontes primárias entre elas o Regimento Interno do Conselho e as atas das reuniões ordinárias e extraordinárias do Conselho Municipal de Saúde de Santo Antônio do Descoberto, registradas no período de janeiro de 2010 a junho de 2012, bem como leis, resoluções e normas que tratam especificamente da participação social no Sistema Único de Saúde. As pesquisas bibliográficas são realizadas através de levantamento e analise de produções textuais em documentos, normas, leis fontes de dados disponíveis em meios eletrônicos e publicações de relevância científica. Com objetivo de verificar se os temas discutidos nas reuniões do conselho estão condizentes com suas atribuições e diretrizes regulamentadoras (14).

\section{Resultados e Discussões}

O Regimento Interno do Conselho Municipal de Santo Antônio do Descoberto (CMSSAD) determina entre as competências descritas na Portaria 333/2003 a formulação de estratégias, controle e acompanhamento do serviço de saúde, bem como as responsabilidades de organizar na Conferência Municipal de Saúde segundo as normativas estabelecida pelo Ministério da Saúde.

A representatividade social segue os critérios de paridade descrita na Lei 8142/90 e a Portaria 333/2003 sendo um total de doze conselheiros distribuídos dentro dos seguintes critérios três representantes do governo e/ou prestadores de serviço indicados pelas entidades prestadoras de serviço e os representantes do governo indicados pelo gestor municipal de saúde, sendo que este considerado membro nato do conselho. 
Tabela 1- Composição dos representantes do Conselho Municipal de Santo Antônio do Descoberto.

\begin{tabular}{c|c|c}
\hline Grupo & Seguimento Social & $\begin{array}{c}\text { Número de } \\
\text { representantes }\end{array}$ \\
\hline $\begin{array}{c}\text { Representantes do Governo. } \\
\text { Representante dos } \\
\text { prestadores de serviços. }\end{array}$ & $\begin{array}{c}\text { Representante da Secretaria Municipal } \\
\text { de Saúde (SMS) }\end{array}$ & 03 \\
\hline $\begin{array}{c}\text { Representante dos } \\
\text { prestadores de serviços } \\
\text { filantrópicos de serviço de } \\
\text { saúde. }\end{array}$ & Fraternidade Eclética Espiritualista Carlos Chagas \\
Universal & 01 \\
\hline $\begin{array}{c}\text { Representante dos } \\
\text { trabalhadores de saúde }\end{array}$ & Trabalhador de estabelecimento privado \\
de saúde & 01 \\
\hline & Associação Comercial & 01 \\
& Associação Juventude Presente & 01 \\
& Associação dos Moradores do Parque \\
Estrela Dalva & 01 \\
Representante dos usuários & Comunidade Rural de Pontizinha & 01 \\
& Associação Ação Social e Comunitária & 01 \\
\hline
\end{tabular}

Os ocupam vagas no CMS-SAD que segundo o Estatuto deveriam ser eleitos em fóruns ampliados, porém não são descritos de que forma e quais devem ser esses fóruns. Ou ponto obsevado é fato do secretario municipal de saúde ser citado como membro nato do CMS-SAD, um fato a ser destacado é que entre o grupo que representa a comunidade temos dois servidores públicos da Secretaria Municipal de Saúde.

Os objetivos e competências descritas no Estatuto interno estão de acordo com Portaria 333/2003 a lei 8142/90. A organização e funcionamento do conselho estabelece a função de conselheiro como de relevância Pública voluntária e garante a dispensa aos trabalhos sem que haja prejuízo aos conselheiros.

O parágrafo II art. 7 do Estatuto do Conselho estabelece que a representatividade da mesa diretora do CMS-SAD será renovada de 2 em 2 anos e no art. 7 e segundo o do 
capitulo IV art. 12 "o mandato de cada Conselheiro será de 4 anos, no entanto, os atuais representantes da mesa diretoras estão na direção a cerca de 6 anos.

O CMS-SAD realizou durante o período de janeiro de 2010 a junho de 2012, 26 reuniões ordinárias e 07 plenárias extraordinárias, as reuniões ordinárias são realizadas rigorosamente segundo o Estatuto interno com uma frequência de 11 reuniões anuais.

Tabela 2 - Reuniões plenárias do Conselho Municipal de Saúde de Santo Antônio do Descoberto.

\begin{tabular}{|ccc|}
\hline Ano & Reuniões ordinárias & Reuniões \\
\hline 2010 & 08 & 04 \\
\hline $\mathbf{2 0 1 1}$ & 11 & 02 \\
\hline $\mathbf{2 0 1 2}$ & 07 & 01 \\
\hline
\end{tabular}

As convocações das plenárias extraordinárias foram feitas pelo presidente do Conselho, para atender as solicitações dos então gestores de saúde, todas para tratar de assuntos financeiros e pendências em parecer técnico de análise de contrapartida do Estado para o Fundo Municipal de Saúde.

As reuniões ordinárias avaliadas mostraram um padrão nos temas discutidos, ficando evidente que os temas de menor relevância, ou que não tem um grande impacto financeiro sempre são enviados ao Conselho para análise de discussão. Enquanto contratos de compras licitações e serviço de impacto financeiro de forma geral só são enviados como informativo não como ponto para discussão e aprovação.

As atribuições exercidas pelos conselheiros do CMS-SAD estabelecidas no Estatuto do Conselho Municipal são:

1. Solicitar, justificadamente documentos referentes a assuntos constantes nas pautas das reuniões;

2. Solicitar diligencia em processos

3. Apreciar e votar os assuntos submetidos ao conselho;

4. Informar a comunidade, entidade ou órgão que represente os assuntos tratados nas reuniões;

5. Submeter a processo de educação permanente; 
6. Comparecer as reuniões;

7. Apresentar projetos e formular soluções no âmbito de competência do conselho;

A inserção de documentação para deliberação do conselho, para ser incluídas na pauta da reunião, deve ser enviada a secretaria executiva do conselho com antecedência mínima de três dias uteis, esses documentos são previamente analisados e ordenados em numeração crescente de acordo com os critérios de pertinência, relevância, tempestividade e precedência. Após a elaboração das pautas é encaminhada a mesa diretora e encaminhadas aos conselheiros com antecedência de dois dias uteis e fixada no mural interno da sede do conselho.

O plenário do Conselho é tido como órgão de deliberação máxima com realização de uma reunião mensal, sempre na última terça-feira útil de cada mês podendo o Presidente convocar reuniões extraordinárias. A convocação extraordinária também pode ser feita maioria absoluta dos membros do conselho, ou seja, sete membros titulares. As reuniões plenárias são abertas ao público, tendo direito de voz apenas após a aprovação da maioria dos conselheiros.

\section{Considerações finais}

As frequências das reuniões ordinárias estão de acordo com o preconizado no Estatuto e número de reuniões extraordinárias vem sendo reduzidas, a cada ano.

Nos casos onde envolve importante impacto financeiro o Conselho apenas toma conhecimento após os gestores já terem realizado a ação, de maneira prática quando isso ocorre, poucas intervenções dois aspectos devem ser considerados primeiramente: a necessidade de capacitação dos conselheiros, o segundo ponto a ser destacado, diz respeito ao domínio dos servidores da saúde, cinco conselheiro que possuem cargo de confiança na Secretaria de Saúde, ocupam as vagas de conselheiro, sendo que desses três são representantes dos servidores da saúde e um representam os prestadores de serviço, pois apesar de manter um cargo comissionado na Secretária Municipal de Saúde também possui clínica privada no município inclusive com convênio para prestação de serviço no Sistema Único de Saúde e por fim um conselheiro que representa o grupo dos usuários, também possui cargo por contrato temporário na Secretaria, essa situação acaba gerando um comprometimento principalmente na fiscalização dos recursos financeiros. 
A participação social na gestão do serviço de saúde sem duvida representa um dos maiores ganhos para os usuários do Sistema Único de Saúde, a efetivação desse direito deve ser feita de forma responsável. Ainda estamos em fase de adaptação nesse recente modo de intervenção social, sendo necessário que gestores, profissionais e usuários tenham consciência da sua importância no exercício pleno da cidadania e o mais breve tenhamos um serviço de saúde de qualidade para todos.

\section{Referências}

1.Aith, FMA. Consolidação do direito sanitário no Brasil. In: Introdução Critica ao Direito à Saúde, in O Direito Achado na Rua, Costa, AB, et al (Org.). Brasília, 2008. .

2.Marchewka, TMN. Saúde mental no contexto do Direito Sanitário In: Introdução Critica ao Direito à Saúde, vol. 4, série O Direito Achado na Rua, Costa, AB et al (Org.). Brasília, 2008.

3 Escorel, S, Nascimento, DR, Edler, FC. Saúde e Democracia: história e perspectivas do SUS. LIMA, NT et alli (org.). Rio de Janeiro: Editora Fiocruz, 2005..

4. Cotta, RMM; Cazal, MM; Martins, PC. Conselho Municipal de Saúde:(re) pensando a lacuna entre o formato institucional e o espaço de participação social. Ciênc. Saúde Coletiva, 2010, 15 (5): 2437-2445. Disponível em: http://www.scielo.br/pdf/csc/v15n5/v15n5a18.pdf. [Acesso em06 dez. 2012].

5. Vasconcelos, W. Observatório da saúde no legislativo: informação e comunicação a serviço da participação social em saúde. Estudos de Direito Sanitário: a produção normativa. Romero, LCP; Delduque, MC (orgs.), Brasília, 2011 p. 163-173.

6.Guizardi, FL, Pinheiro, R. Dilemas culturais, sociais e políticos da participação dos movimentos sociais nos Conselhos de Saúde. Ciência \& Saúde Coletiva, 11(3): 797-805. Rio de Janeiro, 2006. Disponível em: http://www.scielo.br/pdf/csc/v11n3/30994.pdf. [Acesso em 6 de dez. 2012]

7. Wendhausen, Á, Cardoso, SM. Processo decisório e Conselhos Gestores de Saúde: aproximações teóricas. Rev Bras Enferm, Brasília 2007 set-out; 60(5): 579-584.

9. ZelenovskY, MAF. O Tribunal de contas da União e os Conselhos de Saúde: possibilidades de cooperação nas ações de controle. In: Introdução Critica ao Direito à Saúde, vol. 4, série O Direito Achado na Rua. Costa, AB et al. (Org.). Brasília, 2008, p. 333-351.

11.Aith, FMA emergência do direito sanitário como um novo campo do direto. Estudos de Direito Sanitário: a produção normativa. Luiz Carlos Romero e Maria Célia Delduque (Org.), Brasília, 2011 p. 13-39. 
12.Dallari, SG. O direito à saúde na visão de um conselho municipal de saúde. Saúde Pública, Rio de Janeiro, 1996.

13. Alvarenga, MAFP, Rosa, MVF. Apontamentos de Metodologia para a ciência e técnica de redação. Porto Alegre, 2003.

14. Ruíz, JÁ. Metodologia cientifica: guia para eficiência nos estudos, São Paulo, 2008p. 57-60.

8.Brasil. Constituição da República Federativa do Brasil de 1988. Brasília, DF, 5 de out.1988. Disponível em:

<http://www.planalto.gov.br/ccivil_03/Constituicao/Constituicao.htm> [Acesso em: 12 out. 2012.]

10.Brasil. Lei $n^{\circ} 8.080$, de 19 de setembro de 1990. Dispõe sobre as condições para a promoção, proteção e recuperação da saúde, a organização e o funcionamento dos serviços correspondentes e dá outras providências. (Lei Orgânica da Saúde). Diário Oficial [da] República Federativa do Brasil, Brasília, DF, 20 set. 1990. Disponível em: <http://www.planalto.gov.br/ccivil_03/Leis/L8080.htm>. [Acesso em: 12 out. 2012.]

Recebido em: 5.6.2017

Aprovado em:17.7.2017

Silva, RB. Atuação e competência do Conselho Municipal de Saúde Santo Antônio do Descoberto, DF. Revista Cadernos Ibero-Americanos de Direito Sanitário. 2017 jul./set, 6(3):90-100. 